\title{
Complexity absorption: a processual strategic approach to corporate entrepreneurship strategy
}

Haina Zhange

\author{
Correspondence: \\ h.zhang3@lancaster.ac.uk \\ Lancaster University Management \\ School, Lancaster University, \\ Lancaster LA1 4YX, UK
}

\begin{abstract}
In contrast to traditional strategic approaches that are based on complexity reduction, this paper aims to develop an alternative way of understanding entrepreneurial strategy and managing complexity from a processual perspective. The new perspective is developed from a processual perspective integrating insights from an understanding of complexity to engage with philosophical accounts of Chinese processual thought particularly as it is applied to entrepreneurial strategy. The new theoretical framework is empirically investigated through case studies of 30 entrepreneurial organizations in China. The findings confirm that timing and action, context/situation, and efficacy are the three key components in complexity absorption as preferred entrepreneurial strategic approaches.
\end{abstract}

Keywords: Complexity absorption, Entrepreneurial strategy, Chinese processual philosophy

\section{Introduction}

In a period of unprecedented volatility, there is mounting concern of how entrepreneurial organizations can respond to an increasingly complex business environment with the advent of the new technologies that have accompanied the emergence of the internationalization of the economy as an exceptional challenge to existing forms of management control at every level of society. Developed during a period of comparatively stable economic development, the dominant theories of organizations tend to have been founded with the dual objectives of maintaining equilibrium and avoiding uncertainty (Hamel, 2000). The application of complexity theory to organization studies in highly complex environments offers unique insights (e.g., Ashmos et al., 1996; Ashmos et al., 2000; Boisot \& Child, 1999; Brown \& Eisenhardt, 1997; McDaniel, 1997; Stacey, 1995; Wheatley, 1992; Walters \& Bhuian, 2004).

In terms of how organizations deal with asymmetric information in a complex environment, two approaches are suggested: complexity reduction and complexity absorption. Complexity reduction "entails the pursuit of equilibrium via simplistic arrangements", while complexity absorption is achieved "via more complex strategies, structures, and decision processes" (Walters \& Bhuian, 2004, p. 98; cf. Boisot \& Child, 1999; Eisenhardt et al., 2000). The above understanding only captures one dimension of the significance of the complexity absorption concept because there is a neglect of

(c) The Author(s). 2017 Open Access This article is distributed under the terms of the Creative Commons Attribution 4.0 International License (http://creativecommons.org/licenses/by/4.0/), which permits unrestricted use, distribution, and reproduction in any medium, provided you give appropriate credit to the original author(s) and the source, provide a link to the Creative Commons license, and indicate if changes were made. 
the ontological assumptions on which the interpretations are based. Complexity theory posits a processual understanding of reality and complexity absorption is a natural development of the application of complexity theory to better understand social systems and information flows. The substantive model of reality has been retained; hence the full application of the explanatory power of these concepts has been overlooked. Only when the concept of complexity absorption is coupled to a processual ontology as will be discussed in this paper will the full implications of a strategy as process become meaningful. The contemporary dynamic global business environment demands firms be more entrepreneurial; therefore entrepreneurial organizations and strategies seem to be a path to success (e.g., McGrath \& MacMillan, 2000; Morris et al., 2008). This research studies complexity absorption in entrepreneurial organizational settings and suggests it as an effective strategy to deal with complexity.

China's growth is seen as a phenomenon which impacts the whole world. Meanwhile, China is also one of the world's most complex social systems (Keith et al., 2014) and the culture and philosophies that have shaped Chinese civilization for millennia are unique in a number of ways. The Chinese world sees reality in terms of energy flows and natural processes, a view of the world that closely corresponds to that of complexity theory (Herfel et al., 2007). However, the management literature is still characterized by a relative paucity of knowledge about how business strategies are developed to deal with these complexities (e.g., Andriesse \& van Helvoirt, 2010; Chen, 2008; Redding \& Witt, 2007; Yao et al., 2009; Zhang, 2014). The existing studies in this area either follow conventional perspectives, such as an institution-based view (Li et al., 2013; Peng et al., 2008; Peng, 2002) or resource-based view (Fock \& Woo, 2003; Langenberg, 2007; Li et al., 2013; Tsang, 1998). These studies by taking a complexity reduction approach are inadequate to provide effective strategies to deal with complexity in the Chinese world. Therefore, identification of the conceptual foundations of strategy for complexity in Chinese business and the forces driving its success remains unclear.

In China, action, i.e., strategy, is seen differently to the conventional view in which direct action (i.e., complexity reduction) is seen to be a necessity for successful implementation of strategy. Contrary to this conventional view, Chinese aim to achieve a goal with as little direct action as possible. Thus, the strategic intention is to modify one's actions in such a way as to retain a position of relative strength, whilst retaining a long-term objective (i.e., complexity absorption), that of domination rather than destruction of the opponent. In keeping with this view of the world as a dynamic event, i.e., a complex adaptive system, in which continuous change is the only predictable norm, it is accepted that a successful strategy must be founded on the realization that the situation is, in reality, a continuing present. Thus the successful strategies to deal with complexity are to seek for identifying tendencies in the current situation then acting to manipulate circumstances in ways that enable a trend to develop in such a way that the desired objective will emerge by itself (Aligica, 2007). Therefore, in contrast with the ontology of complexity reduction, Chinese philosophical ideas about social practice (as pragmatic in a value rational way) are impossible to study and present at a sophisticated level by employing a rational structural approach (Zhang et al., 2011). One of the objectives of this research is to offer an alternative perspective to study unique nonlinear entrepreneurial strategy to deal with complexity in the Chinese context. 
In order to achieve the research objectives, the entrepreneurial strategies to deal with complexity employed by 30 entrepreneurial organizations in China are investigated through case studies. Entrepreneurial strategy is a construct that specifically manifests entrepreneurship at the firm level (Duane et al., 2009). It has been seen "as a potential source of firms' competitive advantage, a way in which established firms can develop capabilities that are central to their continuing success" (Cooper et al., 2000, p. 120). In the case studies of these 30 organizations, how these organizations achieve development and success in the complex Chinese world by utilizing complexity absorption strategies is explored. This research seeks to represent the dynamic and evolving qualities of strategy in these organizations that have emerged as it has grappled with the lack of institutional support, expanding domestic markets, complicated social networks, dramatic changes in the societies and much more besides. There is much to learn from these entrepreneurial organizations' experiences as they have achieved their current pre-eminent positions in one of the most complex business environments in the world. The argument being presented here is that this has been achieved due to the strategic orientation of entrepreneurs who have adopted a complexity absorbing approach to strategy.

Contributions of this paper are both theoretical and practical. Theoretically, a theoretical framework for entrepreneurial strategies is established to deal with complexities by establishing a link to complexity absorption, a concept that has been only used in information control in the existing literature. By doing so, an alternative ontology of entrepreneurial strategy is offered through a processual theoretical lens. Practically, by developing strategy theories with a deeper understanding of success for entrepreneurial strategies in China based on Chinese otology and real-life examples of Chinese entrepreneurial organizations, this paper provides a strategic mindset to entrepreneurial organizations who actively engage with emerging markets like China where the business environment is more complex than in well-established institutional environments in developed economies.

\section{Theoretical foundation}

\section{Complexity reduction vs. complexity absorption}

The key supposition of the complexity perspective is that the world is constituted by flows of information/events, in which there is always a precarious balance between an emergent order and chaos, between stability and instability (Boisot \& Child, 1999; Holland, 1995; Urry, 2005). "Complexity theory describes the world, as a complex of networks of human and non-human, living and non-living 'actors', continually forming, being maintained and falling apart" (Baskin, 2011, p. 361). The key factor to understand how complexity is managed in contemporary approaches, almost by default, is to manage complexity by employing standardized procedures and measures of performance, i.e., 'complexity reduction' (Boisot 1987, 2000; Boisot \& Child, 1999). The processual alternative introduced in this paper is to manage complexity by diffusing management tasks as widely as possible so that a large number of agents (stakeholders) can participate in the tasks of organizational decision making, i.e., complexity absorption (Boisot 1987, 2000; Boisot \& Child, 1999).

Complexity reduction generally relies on the analysis of quantitative data, allowing modeling and application of generalizable rules, substantially reducing the complexity 
of the situation. This approach employs standardized procedures and measures of performance. In contrast, complexity absorption acknowledges the existence and importance of quantitative data but does not rely on that data when making management decisions; it prefers full knowledge of the implications of a processual understanding of reality, eschewing the substance account reviewed earlier and following the flow of events so as to extract the maximum benefits from the emergent properties that constitute the flow of events thus becoming complex adaptive systems that favor complexity absorption as a mode of practice.

From the perspective of a complexity adaption system (CAS), it is the patterns of emergent order that are not seen or understood by analytical complexity reducing approaches to management control. Because patterns of activity arise from the interaction of the entities that occur at a lower level in the system, at a higher level they are emergent. Thus complexity reducing strategies destroy the meaningfulness of emergent properties which are seen as being like steam from boiling water, simply a by-product of a system rather than being the essential components that comprise the system. Thus, failure to appreciate the potentially infinite number of variables in constant interaction with each other is to dramatically reduce complexity (Boisot, 1987, 2000; Boisot \& Child, 1999).

The preference for complexity reduction is related to the perspective, called the "objective realist perspective", which means that "the social world is made of things in which processes represent the change in things" (Van de Ven \& Poole, 2005, p. 1380). From a complexity science perspective, the world is in a constant state of movement and becoming. They are what is called in complexity theory "dissipative structures"(Herfel et al., 2007) dependent on the flow of their existence, yet paradoxically they are entities in their own right insofar as their inner dynamics can be studied independent of the constituting flow. A very powerful affinity is seen with the idea of the relationship between organizations and their environment, of departments and individuals within that organization; each is at a different level of description in the nested hierarchy that is the organization. Failure to recognize this means that managers assume they are outside the very processes that constitute the organization's existence, thus able to operate independently, free from the constraining effects of the culture, rules and practices on which they depend. From a process or complexity perspective, it is these ingredients that actually constitute them as managers. This means that managers believe they are able to make independent decisions that are outside the flow of events that shape the organization (Van de Ven \& Poole, 1995, 2005). However, these dynamics whilst being intrinsic to the entity being studied i.e., the individual and the department are entirely dependent on the context in which these entities exist. Similarly, for the organization the same sub-processes apply from the organizational context to the individual in the organization. By extension it is natural to see that a living organism is not a separate entity existing independently; instead, it is simply an identifiable pattern constituted by the flows that sustain it; thus we can say that organizations and the organisms that have constituted it are also dissipative structures. In the case of an organization, the flow of energy is also a flow of information that sustains the organization's internal structures and maintains its internal processes.

As long as the energy/information flow remains relatively consistent, the system remains in a stable situation in its relationship with other entities (dissipative structures) 
within the system remaining constant; however, whilst the relationships are constant there will always be turbulence (new information) producing new opportunities/constraints that have the potential to reconfigure the interrelations in the system. Therefore what in conventional, that is in (substantive) terms, are referred to as "objects", and are stabilized patterns of the flow energy/information from the processual perspective advanced here (Boisot \& Child, 1999; Eisenhardt et al., 2000; Holland, 1995).

As these systemic properties are emergent, arising from the relationships and interaction of the parts over time; the whole is "greater than the sum of its parts" and thus the "dissection of a system into its components, either physically or theoretically, destroys that system, and precludes a full understanding of its dynamics and properties" (Capra 1996, p. 29). Thus complexity theory favors a processual approach, stressing relationships, patterns, and contexts (Gell-Mann, 1995).

\section{Chinese ontology of strategy: Complexity absorption}

"Allow the propensity of things to operate outside you as their own disposition dictates; do not project values or desires but adapt constantly to the necessity of their evolution". (Jullien, 1999, p. 39)

Aligica (2007) and Jullien (1999) identify the strategic approach in China as processual efficacy, "a natural disposition". Jullien's points above is consistent with the Chinese worldview that things have their own internal logic, and it is best to allow them to express themselves as this requires no effort. In other words, the best approach to strategy is to begin by identifying the tendencies that the flow of events make manifest, and then work with these tendencies to enhance their natural effects in the most efficient way. In contrast to the conventional strategic approaches, i.e., complexity reduction that sets up a model to serve as a norm for actions, the Chinese strategic approaches concentrate attention on the course of things "in order to detect their coherence and profit from the way that they evolve" (Aligica, 2007, p. 331). Chinese thought promotes complexity absorption (Boisot \& Child, 1999; Cone \& Everett, 2003). Events unfold by means of the interplay of opposition and simultaneous association and can only be understood by understanding the correlations between them. These derive their operative value through the efficacy by which an outcome is revealed. It is this constant interplay of relations that endlessly constitutes reality. "Each of the two aspects subsisting in an interactive relationship with the other and comes into being through it. Reality is apprehended in its becoming, and it is this perspective that one finds at the bottom of the most ancient Chinese thought" (Mair, 1991, p. 377 cf. Hall \& Ames, 1987; Ames, 2003).

Therefore, the core of Chinese philosophy is about managing complexity in a way that maximizes effectiveness and the consequentiality of action (Cheng, 1991; Zhang et al., 2013). Strategy itself is contingent, residing in the engagement of activities. It is necessary to avoid the tendency for complexity reduction, i.e., formulating a goal to which our actions are directed to construct a plan or model to which reality must conform; instead there is a need to try to identify the key factors at play and then allow ourselves to be carried along with the flow of events following the propensity of things, i.e., complexity absorption. Instead of imposing a model on reality, we should allow the 
potential present in the situation to express itself (Jullien, 1999). Only when this processual ontological orientation is adopted, can complexity absorbing strategic approaches be realized.

Following the Chinese perspective, all strategy is necessarily fallible because if the world is flux so an effective strategy must be continuously focused on the now. This strategic orientation aligns with the ontological orientation of complexity absorption that "sees reality as a process devoid of any solid substantial objects that can be relied on to stay the same" (Cavaleri, 2008, p. 476); thus, the strategic stance is the one in which an individual is continuously evaluating on a moment by moment basis the situation in which one finds oneself. In such a situation the strategy for dealing with complexity is to continuously monitor and adjust to changing circumstances. From a processual complexity absorbing perspective, there is a need for strategy to follow the flow in order to maintain a dynamic orientation and harness the energy present in a continuously changing flow of time. Meanwhile, the strategy of complexity absorption is accompanied by the strategy to reduce the options available to the opposition by them to retain a static position, complexity reduction. Such a strategy can be fully understood in the Wei Qi (a GO Game). Rather than following a single-minded approach always seeking absolute victory (i.e., complexity reduction), a successful strategy in Wei $Q i$ is to utilize the opponent's position as a fulcrum to maintain a dynamic stance as the natural result of the need to constantly shift position mirroring the stance of their opponent. The strategic complexity absorption approach is to gain energy and momentum from the opponent's efforts to keep their position, in which timing, context/situation, and action are involved.

Chinese philosophy provides an account of a processual understanding of entrepreneurial strategy. Following the above understanding of strategic complexity absorption approaches, this paper intends to investigate strategies employed in the Chinese context with the empirical case studies of Chinese entrepreneurial organizations, where a process understanding of reality is normative based on Chinese ontology. The complexity absorption approaches will be empirically illustrated and examined according to the processual perspectives provided in Chinese philosophy.

\section{Methodology}

\section{Methods}

In order to explore entrepreneurial strategies in China, this research employed a qualitative research approach, case studies of 30 entrepreneurial organizations, including interviews, direct observation, and memos. In contrast to quantitative research that constitutes an abstract representation of a real situation leading to criticism of its representational accuracy of complexity (i.e., complexity reduction approach), qualitative research emphasizes an understanding of relationships within complexity is a more appropriate method for this topic (i.e., complexity absorption approach). The case study approach is an appropriate research design for the research question of "how" can be answered about a contemporary setting (Faems et al., 2008; Yin, 2003) and multiple direct observations of complex correlative relationships and processes can be facilitated (Eisenhardt, 1989; Eisenhardt \& Graebner, 2007; Faems et al., 2008; Parkhe, 1993). 
According to the well-defined characteristics of entrepreneurial organizations, i.e., high level of work discretion and responsibility for consequences (Chau \& Siu, 2000; Hornsby et al., 1993; Kuratko et al., 1990), 30 entrepreneurial organizations were selected for this research based on the results of pilot studies on case selection. These 30 entrepreneurial organizations are located in five cities in China, Harbin and Shenyang (representing northern China), Beijing (representing central China) and Shenzhen and Sanya (representing southern China). In order to ensure the representativeness of the cases, the samples were selected across different business sectors ranging from service (such as IT, consulting, entertainment, and housekeeping), education, and trading to food and manufacturing. Entrepreneurial organizations selected in this study were more than three years old with a market share and profitability that have been increasing in the most recent three years, which ensure the recent success of their strategic approaches.

In this study, an interview approach was adopted in order to gain an in-depth understanding of the strategic vision and approaches of entrepreneurs. The interview questions are semi-structured. In each interview the same topics were discussed around the related themes of their perceptions of the complexity of the business environment, their strategic approaches to resolve this complexity, the corporate culture and Chinese culture, the kinds of business practices and most importantly the strategic direction of their businesses. The average time of each interview was about one hour. Entrepreneurs are chosen as the main participants in this research as they are more likely to be reflexive on their strategic daily decisions and practice.

In these 30 entrepreneurial organizations, the researcher interviewed 30 entrepreneurs who set up businesses, 23 male and 7 female entrepreneurs. Participants' ages in this study ranged from over 30 to early 60 and their businesses have been successfully running for more than two years. Based on participants' requests, in order to avoid any possibility of personal identification, subjects in this paper are referred to by pseudonyms. Apart from interviews, informal conversations with employees as well as memos and observations of their regular meetings and business practices were also conducted in these organizations. Data from informal discussions and observations were used to triangulate the primary data from interviews.

\section{Data analysis}

Considering the distinctive assumptions implicit in particular ontological, epistemological, and methodological perspectives (Guba \& Lincoln, 1994), this paper follows the interpretive paradigm to do data analysis, as recommended for social science research by Orlikowsk (2002). This interpretive approach, on the assumptions that deeper understandings of phenomena can only be achieved via understanding the interpretations of those phenomena through experiencing them (Shah \& Corley, 2006), suggests that every researcher who is doing this research "will have a unique interpretation of the results" (Labianca, Gray, \& Brass, 2000, p. 241). Rather than replication and theory testing, interpretive data analysis is believed to offer a reasonable interpretation of a phenomenon through experiencing it so that a fundamental understanding of and deeper insight into the phenomenon could be gained (Shah \& Corley, 2006). 
In the detailed analysis of the data the researcher focused on both tangible and intangible items of practice (Orlikowski, 2002) to identify and verify common units of analysis for the purpose of uncovering the implicit rules and meanings that informed the dynamics within each entrepreneurial organization in the study. This was followed by the coding of transcripts and memos made during participant observation in each case. In understanding data analysis, the predefined concept of complexity absorption and the Chinese philosophical perspectives on process and strategy were drawn upon. These sources became the central focal point which informed the interpretation of collaborative interactions within the entrepreneurial organizations in the study. Figure 1 illustrates our data analysis approach and the process of formation of themes. The next section will discuss the primary findings of this research with exemplary quotations that represent the patterns of the views from interviewees across all sample entrepreneurial organizations.

\section{Results and discussions}

\section{Timing and action}

A natural consequence of taking a process view is that time is a key consideration as it is one of the contextual determinants of practice. From this processual perspective, strategy never emerges as it is always emergent as practitioners grapple with the daily or hourly reality of a turbulent world. This follows Bourdieu (1990) in that the real "authors" of everyday coping action are the dynamic relationships that intersect. Prediction is eschewed. Instead the focus is on continuous adaptation-forecasting (complexity reduction) becomes interpretation and high alertness (complexity absorption). Thus the Chinese strategist adapts to circumstances and waits for the appropriate moment to take advantage of the emerging now. Predicting the future while following an ideal model (as suggested in complexity reduction approaches) does not enter into his/her strategic thinking. The continuous monitoring of events and their potential is a process of on-going updating. "What counts is no longer so much what we ourselves personally invest in the situation" but rather "how we exploit the potential emerging from the situations" (Jullien, 1999, p. 22).

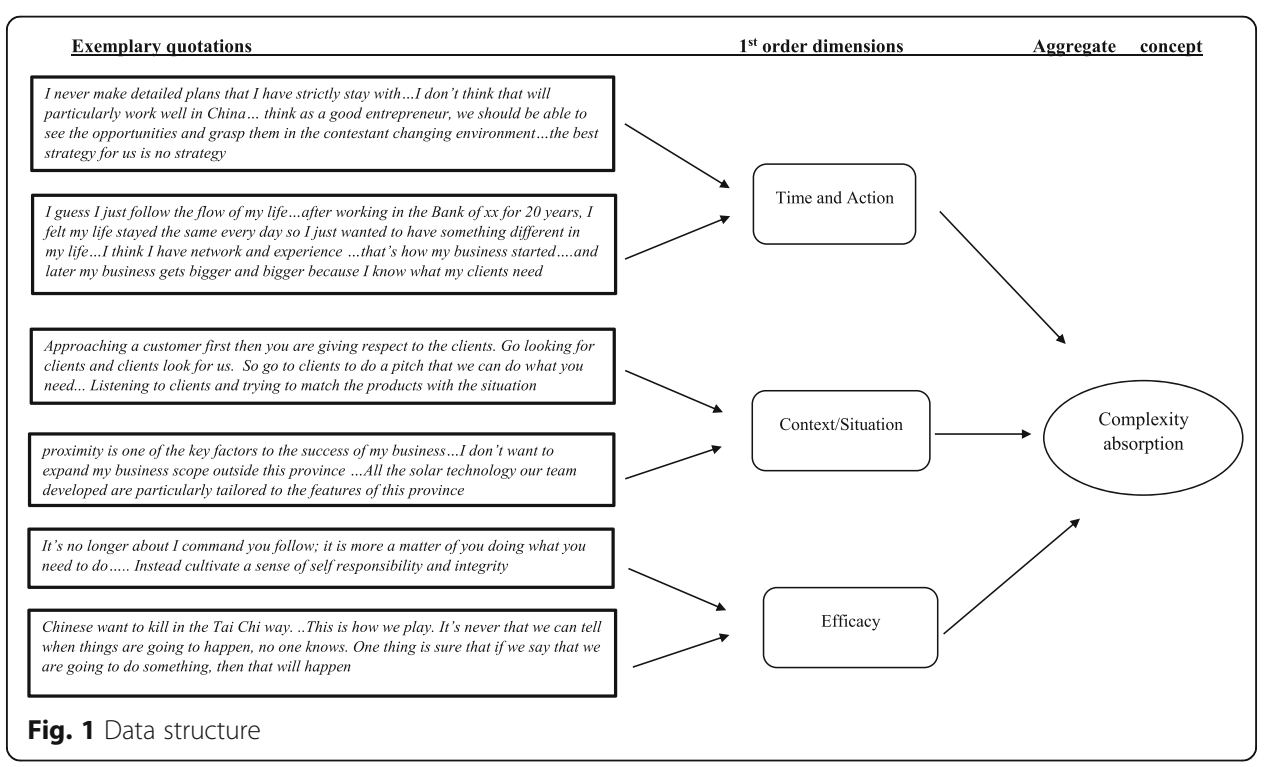


The timing of expansion to the new markets is an essential issue in entrepreneurial strategy (Prashantham \& Young, 2011; Buckley \& Casson, 1981; Yu \& Tse, 2012). Chinese strategic thinking is like Wei Qi (a GO Game), i.e., seeking to fit yourself into the game and using your understanding of your adversary to anticipate their moves and so gain an advantage. This was confirmed by the majority of entrepreneurs interviewed: they placed an absolute priority on staying close to their clients and the market; they do not have any expectations that things will stay the same, but instead emphasize that there are patterns if followed closely that will confer the best chance of staying in the game.

Several times I was thinking of moving the headquarters to Shanghai or Hangzhou where the institutional environments are more supportive to entrepreneurism...but eventually I gave up this idea. Here (Harbin) is the market I serve...all the clients are here...I need to be as close to them as I can be so I can see the opportunities and developmental trends better...(interviewee $L B$ )

I never make detailed plans that I have strictly to stay with...I don't think that will particularly work well in China...our market is so dynamic and full of contingent factors that may change things...I think as a good entrepreneur, we should be able to see the opportunities and grasp them in the constantly changing environment...maybe in a big firm a well-planned strategy will work but certainly not for our type of businesses... the best strategy for us is no strategy... (interviewee MM)

Due to the size of the business, one of the key corporate entrepreneurship strategies is to cope with "the challenges of dissipation of its resource base and derived competitive advantages" in order to secure survival and sustainable growth (Prashantham \& Young, 2011, p. 276). Empirical findings show that Chinese entrepreneurs prefer to gain advantages through "learning from the first" in order to avoid survival risk and failure due to the "liabilities of foreignness" (Sapienza et al., 2006). The market knowledge firms learn from their pioneer experiences which can enable them to penetrate and expand their extant markets through more culturally sensitive approaches. For example, the majority of interviewees indicated that their business might be a pioneering model in the local market but certainly not the one in the larger domestic market. They learnt the models and successful experiences from overseas or from some of the more developed cities in China, and adapted them to their local markets. Nationally they do not want to be a leader but a very astute and attentive follower of trends with a very strong commitment to the local market.

We are very successful in the local market here, for we don't see any competitors now...this business model we use now is what we learnt from the successful business $x x$ in Hangzhou where e-business is far more advanced.... we were all trainees of $x x$ several years ago. After we thought that we had learnt enough about their business model we came back (to our hometown) and set up our own business... we just want to be No. 1 in the local market but the follower of new technology. You know to lead the technology in this area is more costly and we don't want to do that... we don't really need to expand our business to the national market where we would lose our advantage... (interviewee CQ) 
In the Chinese understanding of complexity, the "potential of the situation, cannot be 'seen in advance' (i.e., before the start of operations), but only detected, since it changes all the time" (Aligica, 2007, p. 331). The Chinese strategy practitioner is like a tennis player immersed in the game who instinctively adjusts and responds to his/ her opponent not as they are at a given moment but in their potential positions. "He does so 'on the spot,' 'in the twinkle of an eye, 'in the heat of the moment', that is, in conditions which exclude distance, perspective, detachment and reflection" (Bourdieu, 1990, p. 82). There is no kind of reflective distance allowing for the luxury of observing the unfolding of events from a distance. The Chinese strategist is totally absorbed in the events in order to anticipate the next move.

These strategic practices are based on discipline, restraint and attention to the needs of clients and adversaries. It has no ideology, no core beliefs, no long term plan other than being there and staying close to the game. As Jullien noted in Chinese strategy "constancy rests on a superior understanding of process because it is open to the longer term view in which success is only temporary and no reversal definitive" (1999, p. 202).

"I never have thought that I would leave the Bank of xx, such a prestigious organization and start my own business with my experience in the financial business sector...I guess I just follow the flow of my life...after working in the Bank of $x x$ for 20 years, I felt my life was the same every day so I just wanted to have something different in my life...then one of my friends approached me and encouraged me to provide financial consultancy to customers... I think I have a network and experience so why not...that's how my business started.... and later my business got bigger and bigger because I know what my clients need..." (interviewee ZY)

"I actually started as a hybrid entrepreneur... I once had a very good position in a stateowned enterprise...my position there could help me understand the core of the business and our key customers.... as you know there are a lot of limitations in SOEs and I'm not very satisfied with how this SOE was managed... reforming management in SOEs is almost impossible so I started to think whether I can use all of my resources and network to start a company in this field by myself so I could apply all of the thoughts into real practice...the business was first established when I still worked in that SOE...later on I found my own business was getting bigger and bigger and I could no longer have time to look after two jobs at the same time so I resigned...basically I did the same business but just used different management approaches...I saw all the weaknesses in the management in that SOE so it is easy for me to know what's the best management in my own business by avoiding these mistakes and weaknesses..."(interviewee WH)

As interviewee KS said "Get the timing right then it all follows." These business examples are confirmation that these entrepreneurs appreciate the dynamic nature of events thus predicting the future or promoting a pre-existing plan does not occupy a significant place in their strategic thinking. Whilst a trend may be detected, it changes all the time. Prediction is seen as a waste of time; instead continuous adaptation is the most viable option, relying on sense-making and pure alertness. 
"I never predict and I don't think we can predict when China is developing so rapidly and no one knows what's like the next day...the best strategy for me is to stay close the market and observe every moment of the changes that happen in the market and then take actions to respond to these changes...for example, we first set up our business in Harbin and then later we realized this market is saturated so we took the brave move to our capital (Beijing) and became the first business there...the moment we chose to move was not out of prediction but a truly spontaneous response to the market development and our own vision, i.e. business getting bigger and bigger..." (interviewee $X X$ )

"I first joined the house-keeping sector just as an ordinary house-keeper....that was when I first came to Beijing. I wanted to be successful and I trusted myself...but I didn't know anybody at that time... I think being a house-keeper for a successful businessman gives me an opportunity to closely observe his/her daily life so I could understand the secrets of their success and learn from their experience...I did and I benefited so later I used all these experience to set up my own house-keeping company and it was very successful. I think my success resulted not only from my own knowledge of good service for customers' needs as a house-keeper but also from these successful businessmen's real-life examples..." (interviewee LY)

For these reasons it is absolutely necessary to maintain close connections with markets so as to be able to anticipate the strategic moment- it is about timing. What counts is not so much what is invested but rather how best to exploit the emergent potential of events (Aligica, 2007). The complex is resolved in absolving the self in the time flow and taking actions at the right moment. Hence the arguments support the following proposition:

Proposition 1 Action in timing is an entrepreneurial strategic approach for complexity absorption.

\section{Context/situation}

Operating from the assumptions of complexity reduction, we may have an overly optimistic view of the role of prediction and of its effectiveness; "the Chinese strategist looks at the configuration and its potential and makes the most of its consequences as they unfold" (Aligica, 2007, p. 333), i.e., complexity absorption. Chinese strategic thinking is focused around two ideas: That of a situation (xing), as it evolves as a field of energy; and that of potential (shi), which is a potential in that situation that can be made to work to one's benefit (Jullien, 1999).

A Chinese strategist seeks to avoid forming any conceptions of how things should be, preferring to follow the emerging situation which has its own internal logic in order to benefit from that natural evolution of events (Jullien, 1999). He fosters the skills to act in a way that is in alignment with the emergent situation that leads to everyday strategic outcomes (complexity absorption) rather than deliberate goal-setting activities (complexity reduction).

China is geographically a big country. Developing a wide network and localizing management and investment means that entrepreneurial organizations may have their 
assets and investors in all parts of the country, unlike the UK and European firms who have concentrated their activities in their local markets where they can be geographically more focused. Chinese strategic thinking can offer some insight into the business practices of these entrepreneurial organizations.

"I got this business idea when I toured Australia with my family... I then thought this business model could be applied in China. The next question to me is where I should start it. Although I had a wide business network due to my other businesses, I still wanted to concentrate all strengths in one local market first... using the fist to hit is more powerful than using the palm...I chose Guangzhou first as a starting market because development in Guangdong province is more balanced and there are more developed cities close to Guangzhou if I want to expand my business..." (interviewee YT)

"Proximity is one of the key factors to the success of my business...I don't want to expand my business scope outside this province (Heilongiiang)...All the solar technology our team developed are particularly tailored to the features of this province..." (interviewee KS)

Chinese culture emphasizes the adaptation of the self into various situations by doing the right things at the right time (Sim, 2009). In business interactions, it usually takes calculated and long-term-based strategies to achieve strategic goals, resulting in relative gains or losses. Engagement and confrontation are direct as well as indirect.

"I offered the financial resources to my friend to help him to get through his financial difficulties this year....you know the economy is not very promising this year and I also have difficulties but I would rather investing in him for his business rather than on my own...if you help others in their difficulties, they will help you out in return when I fall into difficulty...I think to invest this long-term friendship is very worthwhile..." (interviewee RA).

"Solar energy wasn't a popular area in China when I first started my business...I know I have to spend a lot on educating people about how economical and environmentally-friendly it is to Chinese... However I think it's worthwhile because sooner or later, the government will pay attention to this green business and by then my business will be the leading company in this area...I think I'm getting the reward now..." (interviewee KS)

In entrepreneurship literature, social capital has been identified and widely accepted as one of the key drivers for the developmental speed of entrepreneurial firms (e.g., Jones \& Coviello, 2005; Rialp et al., 2005). Entrepreneurial firms generally rely on strong ties at start-up, and continuous expansion of the network and social capital are also crucial to the sustainable development of firms (Oviatt \& McDougall, 2005). From the interviews and observations, there is a strong indication of entrepreneurial attitude and "pragmatic" awareness of the need to develop close linkages with the powerful in their business strategies. Their entrepreneurial leadership was particularly skilled at making the right decision at the right time. 
"I think my business was very successful mainly because I knew a powerful person in South Korea who not only holds an influential position which could help me a lot in my business in South Korea but also knows the dynamics and future of business in Asia...I first started my business in trading, bringing products from South Korea to China and later I opened a dumpling restaurant in South Korea bringing unique Chinese products to South Korea...this friend of mine helped me a lot... he also gave me the idea that I should open a coffee shop rather than a tea shop in China as the future generations in China will be heavily influenced by Western culture and habits and coffee houses will be more popular... I followed his advice and my coffee house is one of my most successful businesses now...I now have several businesses in different areas such as coffee houses, restaurants, advertisement, etc. I didn't have a particular plan to open these businesses each time when I entered a new field...I had to develop a crucial connection in this field first and then follow the next step like having this influential person as my friend first before I did all the trading business between South Korea and China..." (interviewee QR)

An awareness of the continuing need to understand the context and leverage the benefits available is verified by the efforts that entrepreneurs make to develop government relationships. As evidenced in most of the interviews, they all mentioned that enormous time and effort were dedicated to managing relationships with local government officials. "If a regulator wants you to do something then you go along with it and in return you hope to get something in return, something that you want" (interviewee KS). For example, "investing in agriculture which is a priority for the Government, you need to follow what they want...I talked to the government of Tianjin and they gave me permission and resources to start an experimental manufacturing base there" (interviewee WL). Further evidence of this priority is the efforts of WL made in Beijing and Shanghai where there is a priority to build a better relationship with government. He lobbied his business idea to the government. Entrepreneurs in all the interviews indicated they considered it was of key importance for their businesses to be confident of the local government as local governments give them an edge in providing sound advice and easy access to markets. Most entrepreneurs indicated this strategy was played mostly "at a dinner" or "playing golf with government officials".

Knowledge is a vital driver of firm growth (Pitelis \& Verbeke, 2007). Another entrepreneurial strategy stressed by these entrepreneurs in this study is that one of the key strategies for their success is being there, being ready and having no preconceived conception of how things may evolve. It is for this reason that interviewees stressed that the competitive edge for their business is great connectivity and local knowledge. Such contextual knowledge is tacit, embedded in skills, know-how, and awareness of the local environment, and is relatively difficult to transfer (Kogut \& Zander, 1993; Teece, 1977), which may become one of the firm's competitive advantages. Quite a few entrepreneurs actually started and developed businesses in that they brought their business models - which had been successful in developed countries or big cities-to the local regions.

"This B to C financial club has run in 13 countries, such as the UK, Ireland, Australia, these developed countries, we just got the license from the headquarters to run it in China last year and so far it has been successful... you know Chinese have 
our own unique culture and consumption habits so we have made quite a few adaptions in the financial products to make it work here." (interviewee YT)

"I grew up here and did all my studies here so I know what local young people need... I think the familiarity with customers and my local network and knowledge helped my business a great deal." (interviewee CQ)

A similar philosophy is evident in quite a few interviewees' statements like "the most successful product is relationship development and tailoring to customer needs". Hamilton (2003) identified the success of Asian marketing strategy as a pull approach.

"Approaching a customer first is best then you are giving respect to the clients. Go looking for clients and clients look for us. So go to clients to do a pitch that we can do what you need... Listening to clients and trying to match the products with the situation." (interviewee YT)

This confirms the point made earlier that a Chinese strategist "is careful not to impose upon the course of events any notion of his own of how things ought to be, since it is from the very evolution of the situation, which follows the course that it is bound to take, he intends to profit" (Jullien, 1999, p. 22). Consistent with Yu and Tse's (2012) suggestions for Chinese entrepreneurship, i.e., "right time, right place, and right people", findings in this research also show that choosing a favorable location by evaluating the situations and developing positive relationships with customers, business partners and their own staff members are crucial to entrepreneurs in order to "get things done".

These entrepreneurial practices are aligned with the strategic thinking encouraged in Chinese philosophy to learn from the context and to apply that learning to the situation in order to more effectively engage in that local context, thus leveraging the learning and integrating the organization more fully into the local context. Building relationships is key to success (Langenberg, 2007; Fock and Woo, 2003; Tsang, 1998); without relationships, it is impossible to understand local conditions and hence the opportunities that are there. The complexity is resolved in absorbing self in the context and relationships.

Hall and Ames put forward a cognitive model and social pattern for Chinese culture (in contrast to a Western one): the underlying logic of Chinese philosophy follows a pattern of aesthetic order, "a consequence of the contribution to a given context of a particular aspect, element, or event that both determines and is determined by the context" (1987, p. 16), characterized by the "primacy of the concrete particular and by its focus on uniqueness, relatedness and coordination" (1987, p. 131). A holistic view is suggested and implicated in Chinese philosophy and therefore context/situation should be understood in the way that all the contingent elements associated with an event (such as social and cultural capital, social structure, relationship, etc.) should be taken into account.

The empirical findings support the proposition that:

Proposition 2 Context/Situation is an entrepreneurial strategic approach for complexity absorption. 
Efficacy

Efficacy is differently understood in different strategic approaches. In a complexity absorption approach, efficacy is realized by successfully recognizing and exploiting the possibilities implicit in a particular situation. In complexity reduction strategic approaches, efficacy is the result of an action in order to coerce or modify things or events to bring about the desired result.

All the interviewees comment that the regulatory environment is totally different because of different governing bodies; it is a matter of adapting to different environments. In China, in contrast to state-owned enterprises (SOEs), entrepreneurial firms lack either the natural relationships with the government and resource support (Peng, Tan, \& Tong, 2004) or the preferential policies of foreign companies (He \& Tian, 2008). The successful establishment of good relationships with local government certainly constitutes the key social capital for entrepreneurial firms. Networks and social capital represent a critical asset for entrepreneurial firms (Coviello, 2006) and can be also seen as the actual and potential resources embedded within and available to the firms (Nahapiet \& Ghoshal, 1998) to build up its competitive advantages.

"Because you can't change the environment you have to change yourself." (interviewee GH)

"We are very good at setting up systems, making sure that we are compliant." (interviewee $\mathrm{XH}$ )

In addition, all the interviewees indicated that making more rules is not the only solution to the compliance regulations that exist in their organizations as that will lead to more problems; therefore, they are trying to focus on getting each employee to recognize that if they know the values of courageous integrity and apply them in what they do then they will be following the rules. Context-specific market knowledge is experiential and tacit (Eriksson et al., 1997); and part of the process of generating context-neutral knowledge "involves the establishment of procedures to transform this experiential, tacit knowledge into objective and explicit knowledge" (Prashantham \& Young, 2011, p. 284). The strategic idea is to drive responsibility down as much as possible by appealing to corporate values and this explicit knowledge. This strategy makes firms operate with effortless efficacy.

"I don't like rules but everyone has to play the game according to the rules in the market. So do I. However, my leadership approach is to make implicit rules first and see if my employees are happy to follow or not. If these rules are also what they think will help the organization and help to work things out more efficiently, they are happy to follow. Then I will make these implicit rules become organization policy. If they don't like these rules, I can see the resistance from their behaviors so I will either adjust them or abandon them. I won't impose rules on my employees. I'm concerned that reinforcement of the rules they don't like will kill their entrepreneurial spirit, which is the core of my organization." (interviewee JR)

"It's no longer about I command you follow; it is more a matter of you doing what you need to do. Don't want to defer, defer, defer up through the organization. Instead cultivate a sense of self-responsibility and integrity." (interviewee ZS) 
In China, strategy is not what you are going to do but what you are not going to do. "If you have a strategy then there is a tendency to focus on that to the detriment of possible alternatives" (interviewee WL). For entrepreneurial organizations, it is not about best strategic practice; it is about best local strategic practice. In the informal discussions with employees in these entrepreneurial organizations, comments were often made, such as "Our decision-maker (the boss) is open to look to where the growth is and move to adapt", and "In our organization, decision-making is top down and execution is bottom up". Therefore, entrepreneurial strategy filters both ways.

"There is a trend. We cannot tell the time it will take or when it will happen but the trend is there. If we were to take the Korean or Japanese way of Tai Kwon Do then you kill others with one hit. Whereas the Chinese want to kill in the Tai Chi way. It takes (with a laugh) four and a half years. This is how we play. It's never that we can tell when things are going to happen, no one knows. One thing is sure that if we say that we are going to do something, then that will happen." (interviewee WX)

"It takes time to know the game... When I first set up my business in this industry, I knew little about it. I thought I am going to earn the profit by planning everything ahead, i.e., studying the market and reading a book on management... but the reality is more complicated than what you can plan... However after being in this industry for a while, I eventually learnt how things work...I now do my business without making so much effort..." (interviewee $L L$ )

The key objective of Chinese thought is to avoid confrontation, through efficacy. As stated in The Art of War, the ability to make opportune use of the propensity of things means that is possible to avoid confrontation. The goal is to intervene in the flow of events upstream where the favorable potentials are identified before they are fully developed. When the "accumulated potential" is deemed to be appropriate then success is assured and the adversary is already defeated. In China, efficacy is achieved by complexity absorption, in contrast to complexity reduction which is through direct action.

As noted earlier such sentiments are founded on an appreciation of the fact that in every situation "we could try to detect the factors whose configuration is favorable to the task at hand; instead of setting up a goal for our actions, we could allow ourselves to be carried along by the propensity of things. In short, instead of imposing our plan upon the world, we could rely on the potential inherent in the situation" (Jullien, 1999, p. 16). As a consequence of the focus on process, entrepreneurial firms experientially acquire contextspecific knowledge with regards to competitors, customers, and institutions concerning cultural, institutional, and business norms. Complexity could be resolved in absorbing all the configurations imposed by all the factors through effortless efficacy.

Proposition 3 Efficacy is an entrepreneurial strategic approach for complexity absorption.

\section{Theoretical contributions}

The paper contributes to both entrepreneurial strategy literature and complexity literature in the following ways: First, complexity theory offer an insightful perspective to 
study organizational responses to the complex environment (e.g., Ashmos et al., 1996; Ashmos et al., 2000; Boisot and Child, 1999; Brown and Eisenhardt, 1997; McDaniel, 1997; Stacey, 1995; Wheatley, 1992; Walters and Bhuian, 2004). Complexity reduction and complexity absorption approaches provide a pair of concepts that allow us to rethink the relationship between different information/management control approaches. They also provide insight into the underlying assumptions that shape strategic thinking when considering strategy from a substantive or processual perspective. However, this theory has not been widely adopted in complexity literature and also the application of this theory has been limited within the information control area. Therefore, this study contributes to extending this theory to the entrepreneurial strategy realm and empirically examining this theory as a strategic approach in real life case studies.

Second, this paper contributes to developing a new theoretical framework for processual entrepreneurial strategic approaches by bringing the complexity absorption concept into strategy literature. By doing so, the value of knowing what works in practice is not only to identify successful actions, but it is as well to better understand how things work. This is based on the assumption that if beliefs are aligned with a clear understanding of what works then practice which is directed by our beliefs will become naturally aligned with the reality of the world around us. An ontological understanding of complexity theory is further developed within a unique context which sees this as normative in both philosophy and entrepreneurial strategic practice. The way that the concept of complexity absorption is developed here and paired with the processual approach favored by a complexity perspective contributes to an understanding that entails providing solutions to issues in complex business environments.

Third, this paper provides an outline of complexity absorption and processual strategic approaches in case studies that analyze entrepreneurial strategic thinking and practice in the Chinese context drawing on complexity theory and the processual Chinese philosophy. The arguments are further supported by empirical case studies of 30 entrepreneurial organizations, illustrating how timing and action, context/situation and efficacy are three key areas of practice in which complexity absorption helps an organization to develop entrepreneurial strategies in order to cope with complexity.

\section{Practical implications}

To summarize the strategy found expressed in the ideas and practices of entrepreneurial organizations this study returns to an account of entrepreneurial strategic practice from a close reading of Chinese philosophy. The philosophy contended guides entrepreneurial strategy in entrepreneurial organizations in China. The interviewees' description of their entrepreneurial strategic direction and the implementation of policies and adjustment of practices to achieve them fits in entirely with the processual approach discussed both in the section on entrepreneurial strategy as process and again in the section of theories of effective practice in the discussion of Chinese strategic thought.

This study is an investigation of the processes by which entrepreneurial organizations have achieved their pre-eminent positions in their respective markets. For the reason noted earlier this perspective informs entrepreneurial strategic practice in these entrepreneurial organizations. Thus, this research is not only useful for an investigator of strategy to comprehend but it is also essential if we are to understand entrepreneurial 
strategy as it is practiced in China. This research finding also has practical applications for foreign entrepreneurs who are planning to operate or are already operating in the Chinese market as it sheds light on what it is that the Chinese firms are doing in terms of strategy thus enabling foreign entrepreneurs to be better equipped to compete successfully in the Chinese market. In addition, the findings suggest that with the going out policy of Chinese entrepreneurs competing in markets around the world this study provides some insights into the entrepreneurial strategies of these overseas Chinese enterprises.

\section{Limitations}

This research makes an initial contribution to providing an ontological understanding of complexity absorption entrepreneurial strategies by adopting Chinese philosophical perspective. The findings contribute to developing the "rigor" dimension of entrepreneurship in China as suggested by Zhang, Yi and Su (2012). However the study is limited in the development of dimension of "relevance" in the fact that all the case studies are conducted in the Chinese context. Although the Chinese context is ideal for the study of complexity due to its dynamic market, dramatic development in a short time, complicated historical and political situation, and ethnic and geographical diversity, further development of the theoretical foundation laid out in this paper requires empirical studies in both developed and developing economies.

Another limitation of this research is the method. Rather than using a multi-level research method that studies different levels within organizations, this research focuses on the top level in entrepreneurial organizations, i.e., entrepreneurs. Although in-depth interviews (approximately one hour each on average) with all the entrepreneurs provided sufficient data and understanding their strategies and primary data from the interviews was triangulated by the data from observations and informal discussions, further research could conduct a multi-level study to include formal interviews with middle level managers and employees for their opinions of strategies to validate these research findings.

\section{Conclusions}

Drawing upon the complexity theory of complexity absorption and Chinese processual philosophy, this paper proposes a new theoretical model of processual entrepreneurial strategic approaches. The empirical findings from the study of Chinese entrepreneurial organizations support the notion that timing, context and efficacy as key elements in a complexity absorption approach are strongly evidenced in entrepreneurial strategic practices, which contribute to the success of their businesses in the Chinese market. The paper has both theoretical and practical importance. Theoretically, the paper extends the scope of the literature of entrepreneurial strategy by developing a new model of entrepreneurial strategic approaches with a processual perspective through building up its link to complexity theory and processual philosophy. Practically, the insight gained from this research contributes to enhancing the understanding of entrepreneurial strategic approaches in a complex market like China and helps businesses prepare their mindsets and strategies when they enter or engage in such markets. 


\section{Acknowledgements}

The author Haina Zhang acknowledges the support of research grant received from the Lancaster University Research Committee (award reference: SGS21/33). The author is also grateful to Professor David Brown for his suggestions on earlier version of this paper.

\section{Funding}

Early Career Small Grant Awarded by the Lancaster University Research Committee, Ref: SGS21/33.

\section{Availability of data and materials}

Raw data cannot be shared due to the agreement with interviewees for confidentiality.

\section{Author's contributions}

Haina Zhang (100\%).

\section{Author's information}

Dr. Haina Zhang is a Senior Lecturer in the Department of Leadership and Management at Lancaster University Management School. She is an Associate Editor of European Management Journal and Co-Track Chair of International Business and International Management of British Academy of Management. Haina has extensive international research experience and her research interest focuses on leadership, organizational behaviour, international business and management, human resource management (HRM), and management in China. She has preferences to adopt an interdisciplinary approach (drawing upon sociology, philosophy and psychology) in her research and bring a philosophical and sociological perspective to study the different ontologies of business and human practice in the Eastern and Western contexts. She has published her research in a number of world-leading journals, such as Journal of Management, Human Resource Management, Journal of Vocational Behaviour, Journal of Business Ethics, and Asia Pacific Business Review.

\section{Publisher's Note}

Springer Nature remains neutral with regard to jurisdictional claims in published maps and institutional affiliations.

Received: 16 June 2017 Accepted: 19 September 2017

Published online: 26 September 2017

\section{References}

Aligica, P. D. (2007). Efficacy, East and West: François Jullien's explorations in strategy. Comparative Strategy, 26(4), $325-337$.

Ames, R. T. (2003). Confucianism and Deweyan pragmatism: A dialogue. Journal of Chinese Philosophy, 30(3-4), 403-417. Andriesse, E. H. S., \& van Helvoirt, B. J. (2010). Regional business systems and private sector development in Southeast Asia. Asia Pacific Business Review, 16(1-2), 19-36.

Ashmos, D. P., Duchon, D., Hauge, F., \& McDaniel, R. R. (1996). Internal complexity and environmental sensitivity in hospitals. Hospital and Health Services Administration, 41(4), 535-553.

Ashmos, D. P., Duchon, D., \& McDaniel, R. R. (2000). Organizational responses to complexity: The effect on organizational performance. Journal of Organizational Change Management, 13(6), 577-594.

Baskin, K. (2011). How Chinese thought can lead the transformation in management practice. Chinese Management Studies, 5(4), 354-367.

Boisot, M. (1987). Information and organizations: The manager as anthropologist. London, UK: Fontana Press.

Boisot, M. (2000). Is There a complexity beyond the reach of strategy? Emergence, 2(1), 114-134.

Boisot, M., \& Child, J. (1999). Organizations as adaptive systems in complex environments: The case of China. Organization Science, 10(3), 237-252.

Bourdieu, P. (1990). The logic of practice. Cambridge: Polity Press.

Brown, S. L., \& Eisenhardt, K. M. (1997). The art of continuous change: Linking complexity theory and time-paced evolution in relentlessly shifting organizations. Administrative Science Quarterly, 42(1), 1-34.

Capra, F. (1996). The web of life: A new synthesis of mind and matter. London, UK: Harper Collins.

Cavaleri, S. A. (2008). Are learning organizations pragmatic? The Learning Organization, 15(6), 474-485.

Chau, L. L. F., \& Siu, W. S. (2000). Ethical decision-making in corporate entrepreneurial organizations. Journal of Business Ethics, 23(4), 365-375.

Chen, X. P. (2008). Independent thinking: A path to outstanding scholarship. Management and Organization Review, 4(3), 337-348.

Cheng, C. Y. (1991). New dimensions of Confucian and Neo-Confucian philosophy. Albany, NY, US: State University of New York Press.

Cone, M. H., \& Everett, A. M. (2003). Information asymmetry and management control issues in a Sino-French IJV in China. Euro Asia Journal of Management, 13, 107-122.

Cooper, A. C., Markman, G. D., \& Niss, G. (2000). The evolution of the field of entrepreneurship. In G. D. Meyer \& K. A. Heppard (Eds.), Entrepreneurship as strategy (pp. 115-133). Thousand Oaks, CA: Sage Publications.

Duane, R., Covin, J. G., \& Kuratko, D. F. (2009). Conceptualizing corporate entrepreneurship strategy. Entrepreneurship Theory and Practice, 33(1), 19-46.

Eisenhardt, K. M. (1989). Building theories from case study research. Academy of Management Review, 14(4), 532-550.

Eisenhardt, K. M., Brown, S. L., \& Neck, H. M. (2000). Competing on the entrepreneurial edge. In G. D. Meyer \& K. A. Heppard (Eds.), Entrepreneurship and strategy (pp. 49-62). Thousand Oaks, CA: Sage Publications.

Eisenhardt, K. M., \& Graebner, M. E. (2007). Theory building from cases: Opportunities and challenges. Academy of Management Journal, 50(1), 25-32. 
Faems, D., Janssens, M., Madhok, A., \& Van Looy, B. (2008). Toward an integrative perspective on alliance governance: Connecting contract design, trust dynamics, and contract application. Academy of Management Journal, 51(6), 1053-1078. Fock, H. K. Y., \& Woo, K. (2003). The China market: strategic implications of guanxi. Business Strategy Review, 9, 33-43. Gell-Mann, M. (1995). Complex adaptive systems. In Santa Fe Institute Studies in The Sciences Of Complexity-Proceedings Volume (Vol. 22, pp. 11-11). Addison-Wesley Publishing Co.

Guba, E. G., \& Lincoln, Y. S. (1994). Competing paradigms in qualitative research. In N. K. Denzin \& Y. S. Lincoln (Eds.), Handbook of qualitative research (pp. 105-117). Thousand Oaks, CA: Sage.

Hall, D., \& Ames, R. T. (1987). Thinking through Confucius. Albany, NY: State University of New York Press.

Hamel, G. (2000). Leading the revolution. Boston: Harvard Business School Press.

Herfel, W., Rodriques, D., \& Gao, Y. (2007). Chinese medicine and the dynamic conceptions of health and disease. Journal of Chinese Philosophy, 34(s1), 57-79.

Holland, J. H. (1995). Hidden order: How adaptation builds complexity. Reading, MA: Addison-Wesley.

Kuratko, D. F, Montagno, R. V, \& Hornsby, J. S. (1990). Developing an Intrapreneurial Assessment Instrument for an Effective Corporate Entrepreneurial Environment. Strategic Management Journal, 11, 49-58.

Hornsby, J. S., Naffziger, D. W. Kuratko, D. F., \& Montagno, R. V. (1993). An interactive model of the corporate entrepreneurship process. Entrepreneurship: Theory and Practice, 17(2), 29-38.

Jullien, F. (1999). The propensity of things: Towards a history of efficacy in China. New York: Zone Books.

Keith, M., Lash, S., Arnoldi, J., \& Rooker, T. (2014). China constructing capitalism: Economic life and urban change. London: Routledge.

Labianca, G., Gray, B., \& Brass, D. J. (2000). A grounded model of organizational schema change during empowerment. Organization Science, 11(2), 235-257.

Langenberg, E. A. (2007). Guanxi and business strategy: Theory and implications for multinational companies in China. Springer Science \& Business Media.

Li, X., Zhao, X., \& Zhang, J. (2013). Corporate entrepreneurship, informal ties, and firm performance: Evidence from China. Frontiers of Business Research in China, 7(1), 26-58.

Mair, V. H. (1991). The language of Chinese thought. Philosophy East and West, 41(3), 373-386.

McDaniel, R. R. (1997). Strategic leadership: A view from quantum and chaos theories. Health Care Management Review, 22, 21-37.

McGrath, R. G., \& MacMillan, I. C. (2000). The entrepreneurial mindset: Strategies for continuously creating opportunity in an age of uncertainty. Boston: Harvard Business School Press.

Morris, M. H., Kuratko, D. F., \& Covin, J. G. (2008). Corporate entrepreneurship and innovation. Cincinnati, OH: Thomson/ SouthWestern Publishers.

Orlikowski, W. J. (2002). Knowing in practice: Enacting a collective capability in distributed organizing. Organization Science, 13(3), 249-273.

Parkhe, A. (1993). "Messy" research, methodological predispositions, and theory development in international joint ventures. Academy of Management Review, 18(2), 227-268.

Peng, M. W. (2002). Towards an institution-based view of business strategy. Asia Pacific Journal of Management, 19(2-3), 251-267.

Peng, M. W., Wang, D. Y. L., \& Jiang, Y. (2008). An institution-based view of international business strategy: A focus on emerging economies. Journal of International Business Studies, 39(5), 920-936.

Redding, S. G., \& Witt, M. A. (2007). The future of Chinese capitalism. Oxford, UK: Oxford University Press.

Shah, S. K., \& Corley, K. G. (2006). Building better theory by bridging the quantitative-qualitative divide. Journal of Management Studies, 43(8), 1821-1835.

Stacey, R. D. (1995). The science of complexity: An alternative perspective for strategic change processes. Strategic Management Journal, 16(6), 477-495.

Tsang, E. W. K. (1998). Can guanxi be a source of sustained competitive advantage for doing business in China? The Academy of Management Executive, 12(2), 64-73.

Urry, J. (2005). The complexities of the global. Theory, Culture \& Society, 22(5), 235-254.

Van de Ven, A. H., \& Poole, M. S. (1995). Explaining development and change in organizations. The Academy of Management Review, 20(3), 510-540.

Van de Ven, A. H., \& Poole, M. S. (2005). Alternative approaches for studying organisational change. Organisation Studies, 26(9), 1377-1404

Walters, B. A., \& Bhuian, S. N. (2004). Complexity absorption and performance: A structural analysis of acute-care hospitals. Journal of Management, 30(1), 97-121.

Wheatley, M. J. (1992). Leadership and the new science. San Francisco, CA: Berrett Koehler Publishers.

Yao, X., Wen, W., \& Ren, Z. (2009). Corporate entrepreneurship in the enterprise clusters environment-Influence of network resources and entrepreneurial orientation on firm performance. Frontiers of Business Research in China, 3(4), 566-582.

Yin, R. K. (2003). Case study research: Design and methods. Thousand Oaks, CA: Sage.

Yu, F. L. T., \& Tse, P. W. P. (2012). "Right Time, Right Place, and Right People" and Chinese entrepreneurship: A case study of Taiwan's Din Tai Fung Dumpling House. Frontiers of Business Research in China, 6(1), 96-119.

Zhang, H., Cone, M. H., Everett, A. M., \& Elkin, G. (2011). Aesthetic leadership in Chinese business: A philosophical perspective. Journal of Business Ethics, 101(3), 475-491.

Zhang, H., Cone, M. H., Everett, A. M., \& Elkin, G. (2013). Contextualizing transformational leadership theories in China: A Confucian perspective. Frontiers of Business Research in China, 7(2), 189-218.

Zhang, S., Yi, X., \& Su, X. (2012). Rigor and relevance: On the development of entrepreneurship research in China. Frontiers of Business Research in China, 6(3), 418-434.

Zhang, Z. (2014). Hierarchical dynamic capabilities and strategic entrepreneurship in changing industrial environments. Frontiers of Business Research in China, 8(3), 388-410. 